Available online on 15.09.2018 at http://jddtonline.info

Journal of Drug Delivery and Therapeutics

Open Access to Pharmaceutical and Medical Research

JDDT

C) 2011-18, publisher and licensee JDDT, This is an Open Access article which permits unrestricted non-commercial use, provided the original work is properly cited

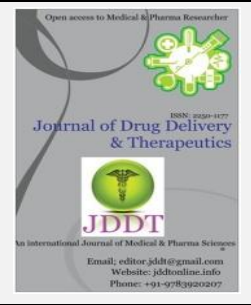

Open $\bigcirc$ Access

Review Article

\title{
INNOVATIVE AND NOVEL STRATEGY: MICROSPONGES FOR TOPICAL DRUG DELIVERY
}

\author{
Jyoti* and Kumar Sandeep \\ ASBASJS Memorial College of Pharmacy, Bela, Ropar, Punjab, India
}

\begin{abstract}
Microsponge type of drug delivery is the latest technology which has been introduced in topical skin care, drug products to facilitate the controlled release of the active medicament into the skin in order to reduce systemic exposure and control local cutaneous reactions to active drugs. Microsponge can be loaded into a topical route of drug delivery system for the residue of dosage form of skin and thus controlled release drug delivery system is achieved and in return improving the patient compliance by providing target drug delivery system and prolonging dosage intervals. Microsponge is polymeric delivery systems composed of porous microspheres. They are tiny sponge-like spherical particles and posses large porous surface area. Furthermore, they may enhance stability, reduce side effects, improve patient compliance and modify drug release. Microsponges are the polymer-based microspheres system that has the capacity to entrap a wide variety of substances, and can then be incorporated into a different formulation.
\end{abstract}

Keywords: Microsponge Delivery System, Quasi- emulsion solvent diffusion.

Article Info: Received 07 Aug, 2018; Review Completed 30 Aug 2018; Accepted 30 Aug 2018; Available online 15 Sep 2018

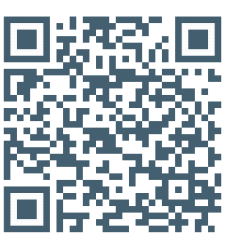

Cite this article as:

Jyoti, Kumar S, Innovative and novel strategy: Microsponges for topical drug delivery, Journal of Drug Delivery and Therapeutics. 2018; 8(5):28-34 DOI: http://dx.doi.org/10.22270/jddt.v8i5.1885

*Address for Correspondence:

Jyoti, ASBASJS Memorial College of Pharmacy, Bela, Ropar, Punjab, India

\section{INTRODUCTION}

Microsponge is Neoteric technology, which provides extended release of pharmaceutical active ingredients ${ }^{1,2}$ and mostly used for topical administration. Now a day the major challenge to the pharmaceutical industry is to control the rate of delivery of active pharmaceutical ingredient to a pre-determined site. So to improve efficacy and patient compliance, researcher focused on designing of different controlled release drug delivery systems. In 1987, Won was developed the microsponge technology and the original patents were authorized by Advanced Polymer System, Inc. ${ }^{3}$ Microsponge having a myriad of interconnected size ranging voids of particle from 5-150 $\mu \mathrm{m} .^{4}$ The main purpose of this delivery system to achieved desired concentration of the drug in blood in the microsponge delivery systems which is therapeutically more effective and non-toxic for long periods in the recent study. Primarily microsponge is the use for transdermal drug delivery system. ${ }^{5,} 6$ Various methods for preparation of microsponge drug delivery systems studied.

A typical $25 \mu \mathrm{m}$ sphere can have up to 250000 pores and have an internal pore structure equivalent to 10 feet in length and this results in a large reservoir type system within each microsponge, which can be loaded with up to its own weight of the active agent. The microsponge particles are too large to be absorbed into the skin. 7,8

Properties of drug for loading into microsponge ${ }^{9,10,}$

1. It must be fully miscible in monomer otherwise, should be made miscible by addition of a small amount of a water immiscible solvent.

2. It should be watered immiscible or at most only slightly soluble. 
3. With respect to monomers it should be inert.

4. The solubility of active ingredients in the vehicle must be checked to avoid cosmetic problems; otherwise the vehicle will evacuate the microsponge before the application.

5. The spherical structure of microsponge should not faint.

6. Design of Polymer for the active must be optimized for a given time period for required release rate. It must be stable in contact with polymerization catalyst and states of polymerization.

\section{Advantages of microsponge drug delivery system ${ }^{12}$}

1. Microsponge is act as a controlled drug delivery system.

2. Drug directly applied to target organs.

3. It increases stability of drugs.

4. These are capable of absorbing skin secretions and lessen the oiliness.

5. Enhanced product performance.

6. Reduced irritation and hence improved patient compliance.

7. Improved product elegance.

8. It can improve efficacy in the treatment.

9. It can also improve bioavailability of the drugs

10. Flexibility to develop novel product forms.

11. MDS has a wide range of chemical stability and are easy to formulate.

12. Microsponge systems are non-irritating, nonmutagenic, non-allergenic and non-toxic.

13. Microsponge system can reduce significantly the irritation of effective drugs

14. Without reducing their efficacy, it can prevent excessive accumulation of ingredients within the skin surface.

\section{Potential feature of microsponge drug delivery} system $^{13}$

- Improved oil control as it can absorb oil up to 6 times its weight.

- Microsponge system compatible with vehicles and active ingredients.

○ Self sterilizing as average pore size is $0.25 \mu \mathrm{m}$ where bacteria cannot penetrate.

- These are non-irritating, non mutagenic, non allergenic and nontoxic.

○ Release is extended up to 12 hours.

- Microsponge system stable in the range of $\mathrm{pH} 1$ to 11 , temperature up to $130^{\circ} \mathrm{C}$.

- Liquids can be converted into powders by improving material processing.

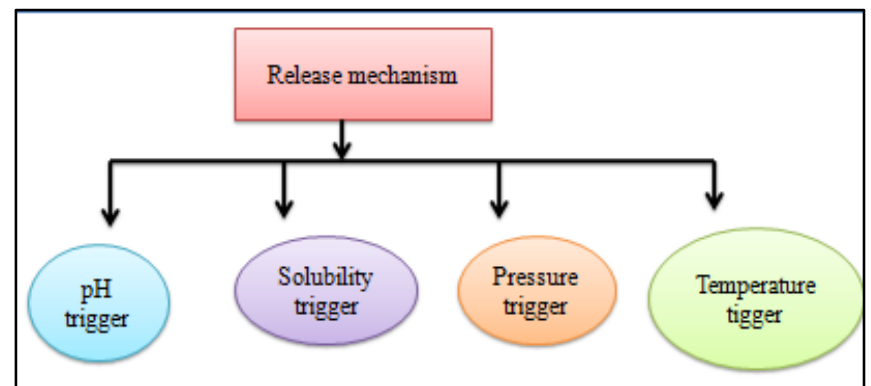

Figure 1: Programmable release from microsponges

\section{Pressure triggered systems ${ }^{14}$}

Microsponge system releases the entrapped material when pressurized/rubbed; the amount released depends upon special characteristics of the sponge. The microsponge best suited for a given application may be optimized by varying the type of material and different process variables.

\section{Temperature triggered systems ${ }^{15}$}

Some active ingredients loaded in microsponge can be too viscous at room temperature to flow spontaneously into the skin. The flow rate can be increased by increasing the skin temperature and hence release. ${ }^{16,}{ }^{17}$ So it is possible to regulate the release of substances from the microsponge by modulation of temperature.

\section{pH triggered systems}

Triggering the pH-based release of the active can be achieved by modifying the coating on the microsponge. This has many applications in drug delivery.

\section{Solubility triggered system ${ }^{18}$}

Microsponge loaded with water-soluble ingredients will release the ingredient in the presence of water. The release rate of active ingredients can be triggered in the presence of aqueous medium. This release may be achieved based on the ability of the external medium to dissolve the active, the concentration gradient or the capability to swell the microspore network.

Drugs explored in the microsponge delivery system ${ }^{19}$, 20, 21, 22

Paracetamol

Benzoyl peroxide

Ketoprofen

Miconazole

Fluconazole

Curcumin

Acyclovir sodium

Retinol

Erythromycin

Tretinoin

Hydroquinone

Ibuprofen

Prednisolone

Mupirocin

\section{Polymers used for the preparation of microsponges}

Eudragit RS 100 and RL 100

* Ethylcellulose

* Polystyrene

* Acrylic polymer

* PHEMA

\# Carbopol 934 


\section{PREPARATION OF MICROSPONGES DRUG DELIVERY SYSTEM ${ }^{23-27}$}

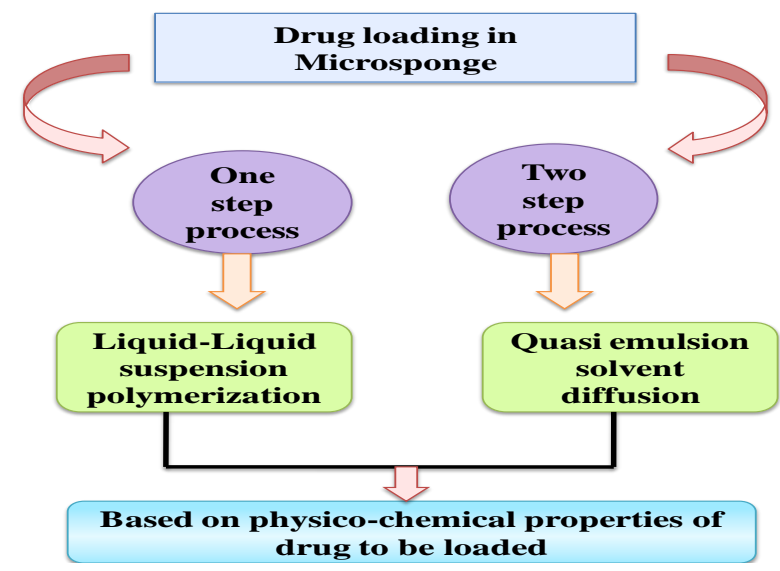

Figure 2: One step and two step preparation of microsponges

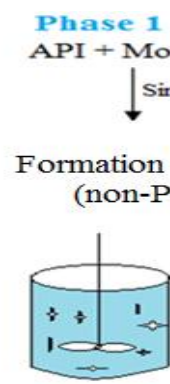

Monomer
$\downarrow$ Simple Mixing

ormation of Solution (non-Polar)

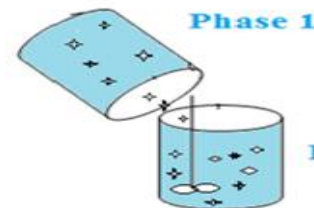

Continuous Stirring for $12 \mathrm{~h}$

Filteration of Microsponges and drying at $40^{\circ} \mathrm{C}$ for $12 \mathrm{~h}$
1. Liquid-liquid suspension polymerization ${ }^{28,29,30}$

The porous microsphere based microsponges are prepared by the suspension polymerization method. In this polymerization technique the immiscible monomers are first dissolved with active ingredients in a suitable solvent and are then dispersed in the aqueous phases which consist of surfactant or suspending agents that are used for the formation of suspension. The polymerization is then activated by increasing temperature or irradiation or by addition of catalyst. The polymerization process continues until the reservoir type of system with spherical structure is formed. After the polymerization process the solvent is removed, leaving the microsponges.

Figure 3: Formation of Suspension for Preparation of Liquid-Liquid Suspension Polymerization.

\section{Quasi-emulsion solvent diffusion ${ }^{31,32,33}$}

Quasi-emulsion solvent diffusion technique (two-step process) is used for the preparation of Porous microsphere (microsponges). In this method an inner phase containing polymer such as eudragit dissolved in solvent like ethyl alcohol. The drug is slowly added to the polymer solution, then dissolved under ultrasonication at the temperature $35^{\circ} \mathrm{C}$ and plasticizer such as triethylcitrate (TEC) is added in order to assist the plasticity. The inner phase is then poured into external phase containing polyvinyl alcohol and distilled water with continuous stirring for 2 to 3 hours. Then, the mixture is filter to separate the microsponges. The microsponges is then washed and dried in an oven at $40^{\circ} \mathrm{C}$ for 10 to $12 \mathrm{~h}$.

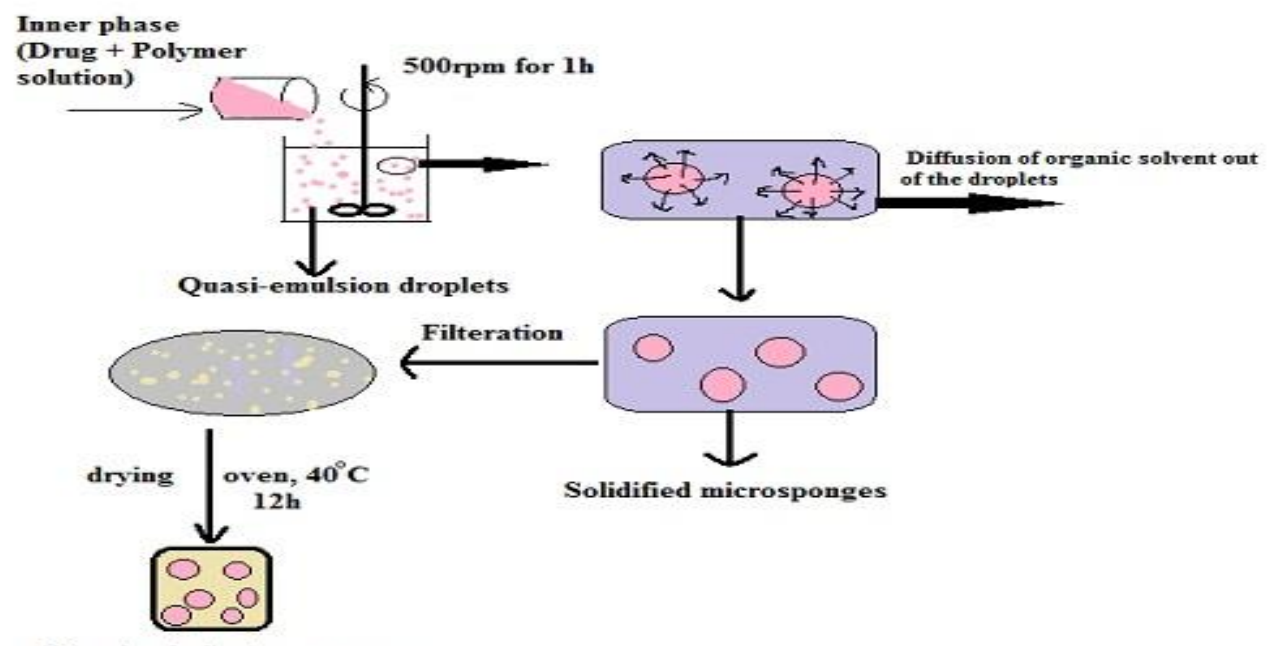

Drug loaded microsponges

Figure 4: Quasi-emulsion solvent diffusion method. 


\section{MECHANISM OF ACTION ${ }^{34}$}

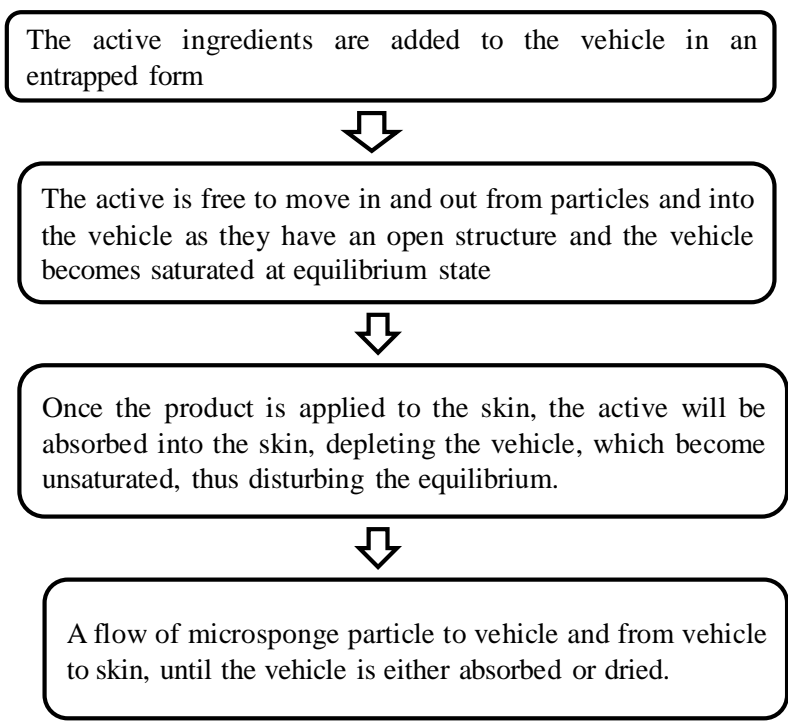

Figure 5: Release mechanism of microsponge drug delivery

Table 1: Optimum values for microsponges formulation

\begin{tabular}{|l|l|l|}
\hline Sr.no & Specification & Optimum value \\
\hline 1 & Drug and polymer ratio & $1: 1,1: 2,1: 3,2: 1 \& 3: 1$ \\
\hline 2 & Amount of drug $(\mathrm{mg})$ & $100-300$ \\
\hline 3 & Polyvinylalcohol $(\mathrm{mg})$ & 100 \\
\hline 4 & Inner phase solvent $(\mathrm{ml})$ & Ethyl alcohol \\
\hline 5 & Amount of inner phase solvent & 10 \\
\hline 6 & Amount of water in outer phase $(\mathrm{ml})$ & 100 \\
\hline 7 & Temperature of inner phase & $25^{\circ} \mathrm{C}$ \\
\hline 8 & Type of process & Magnetic stirrer and bath sonicator \\
\hline 9 & magnetic stirrer speed & $1000 \mathrm{rpm}$ \\
\hline
\end{tabular}

\section{EVALUATION METHODOLOGY OF MICROSPONGE ${ }^{35,36,37}$}

Particle size evaluation-The particle size distribution is evaluated using optical microscope or electron microscope. Particle size determination of Microsponge can be performed by laser light diffractometry or other suitable method. The values (d 50) can be expressed for all formulations as mean size ranges. Particle size greater than $30 \mu \mathrm{m}$ can give gritty feeling and hence particles sizes between 10 and $25 \mu \mathrm{m}$ are used in the final formulation.

Morphology and surface topography- In the morphological study of microsponge topography various techniques are used such as the photon correlation spectroscopy (Pcs), Transmission electron spectroscopy (TEM), scanning electron microscopy (SEM).

Determination of loading efficiency: The loading efficiency $(\%)$ of the microsponges can be calculated as follows:-

Loading efficiency

$=\frac{\text { Actual Drug Content in microsponges }}{\text { Theoretical Drug Content }} \times 100$
Determination of production yield: The production yield of the microsponges can be determined by:

$$
\begin{aligned}
& \text { Production Yield } \\
& =\frac{\text { Practical Mass of Microsponges }}{\text { Theoretical Mass (Polymer }+ \text { Drug) }} \times 100
\end{aligned}
$$

Determination of true density- The true density of the microsponge can be measured using an ultrapycnometer in the presence of helium gas and is calculated from a mean of repeated determinations.

Compatibility study- It can be studied by thin layer chromatography (TLC) and Fourier Transform Infra-red spectroscopy (FT-IR). Effect of polymerization on the crystallinity of drug can be studied by powder X-ray diffraction (XRD) and differential scanning calorimetric.

Release evaluation: Release of microsponges can be controlled through diffusion or other triggering mechanism such as moisture, $\mathrm{pH}$, friction, temperature. This release mechanism used to enhance product aesthetics.

Resiliency: For the production of bullets a particle that is softer or firmer according to the needs of the final formulation viscoelastic properties of the microsponge 
can be modified. Increased cross-linking tends to decrease the rate of release.

Stability study: Gel formulation is subject to stability testing as per ICH norms. Gel fill in clean, lacquered, collapsible aluminum tubes, and various replicates kept at $40 \pm 2{ }^{\circ} \mathrm{C}$ and $75 \pm 5 \%$ relative humidity in a humidity Chamber. Gel assessed for change in appearance, $\mathrm{pH}$ and in vitro release profile at an interval of 30,60 and 90 days.

\section{APPLICATION OF MICROSPONGE}

It offers the formulator range of alternative to develop the drug and cosmetic products. Over-the-counter products that incorporate microsponge drug delivery system include numerous moisturizers, specialized rejuvenated products, and sunscreens. ${ }^{38-42}$

Topical drug delivery using microsponge technology ${ }^{43}$ - (A) Benzoyl peroxide (BPO) is commonly used in topical formulations for the treatment of acne and athlete's foot. Controlled release of BPO of the microsponge delivery system to the skin could reduce the side effect.

(B) A Microsponge based topical formulation of mupirocin, used as antibiotic for skin infection, to achieve sustained drug release. The increased absorption of mupirocin in the skin from microsponge delivery system suggests the delivery system to be an efficient system for treatment of primary and secondary skin infections as compared to conventional mupirocin emulgel and marketed mupirocin ointment.

Oral drug delivery using microsponge technologyThe Microsponge system provides the controlled delivery of oral medications to the lower gastrointestinal tract, where upon exposure to specific enzymes it will be released in the colon. It has been shown that microsponge system enhances the solubilization of poorly soluble drugs by entrapping these drugs in their pores. Controlled oral delivery of ketoprofen prepared with Eudragit RS100 by quasi emulsion solvent diffusion method and subsequently tablet of microsponge was prepared by the direct compression method results show that compressibility was much improved in the physical mixture of the drug and the polymer due to the plastic deformation of sponge like microsphere structure. ${ }^{44-50}$

Microsponge used for bone and tissue engineeringBone like compounds were obtained by the mixing prepolymerized powder of polymethyl methacrylate monomer with two aqueous dispersion of tricalcium phosphate grains and calcium deficient hydroxyapatite powders. The final compound appeared to be porous and developed as microsponge.

Table 2: List of marketed products based on microsponges ${ }^{51,52,53}$

\begin{tabular}{|l|l|l|}
\hline Product Name & Pharmaceutical Uses & Manufacturer \\
\hline Glycolic Acid Moisturizer w/SPF 15 & Anti-Wrinkles, soothing & AMCOL Health \& Beauty Solution \\
\hline Retin A Micro & Acne vulgaris & Ortho-McNeil Pharmaceutical, Inc \\
\hline Line Eliminator Dual Retinol Facial Treatment & Anti-wrinkle & Avon \\
\hline Retinol 15 Night cream & Anti-wrinkles & Sothys \\
\hline Retinol cream & Helps maintain healthy skin & Biomedic \\
\hline EpiQuin Micro & Hyper pigmentation & SkinMedica Inc \\
\hline Sports cream RS and XS & Anti-inflammatory & Embil Pharmaceutical Co. Ltd. \\
\hline Salicylic Peel 20 & Excellent exfoliation & Biophora \\
\hline Oil free matte block SPF 20 & Sunscreen & Dermalogica \\
\hline Lactrex ${ }^{\text {TM12\% }}$ & Moisturizing Cream & SDR Pharmaceuticals, Inc \\
\hline Ultra Guard & Protects baby's skin & Scott Paper Company \\
\hline
\end{tabular}

Table 3: Patents filed on microsponges ${ }^{57}$

\begin{tabular}{|l|l|}
\hline \multicolumn{1}{|c|}{ Patent Number } & \multicolumn{1}{c|}{ Patent Name } \\
\hline $\mathbf{5 1 0 0 7 8 3}$ & Weighted microsponge for immobilizing bioactive material \\
\hline $\mathbf{1 2 8 8 3 7 0}$ & Weighted collagen microsponge \\
\hline $\mathbf{4 9 9 7 7 5 3}$ & Weighted collagen microsponge for immobilizing bioactive material \\
\hline $\mathbf{1 2 7 5 9 5 5}$ & Weighted microsponge \\
\hline $\mathbf{4 8 6 3 8 5 6}$ & Weighted collagen microsponge for immobilizing bioactive materials \\
\hline $\mathbf{4 8 6 1 7 1 4}$ & Weighted collagen microsponge for immobilizing bioactive material \\
\hline $\mathbf{0 2 1 7 9 1 7}$ & Weighted microsponge for immobilizing bioactive material \\
\hline $\mathbf{1 9 8 0 5 6 6 9 4}$ & Weighted microsponge for immobilizing bioactive material \\
\hline $\mathbf{4 0 9 2 3 8 1}$ & Weighted microsponge for immobilizing bioactive material \\
\hline & $\begin{array}{l}\text { Methods of fabricating microsponge deuterated hydrocarbon polymer } \\
\text { targets which emit neutrons when irradiated by high energy beams }\end{array}$ \\
\hline
\end{tabular}




\section{FUTURE EXPECTANCY}

Microsponge is the present day novel technology, which is the mostly developed for the topical delivery system and recently for oral administration. It provides various kinds of advantages. Microsponges are carefully designed pharmaceutical active ingredient that deliver the drug effectively at the target site with the minimum dose and also to enhance stability, reduce side effects and control drug release. The real face off in the future is the development of the delivery system for the oral peptide delivery by altering the ratio of polymers. Microsponges will be an excellent drug delivery system. Microsponges drug delivery system that can accurately control the release rates to the specific sites of the body will be sought in great detail in the years to come that have an immense on the health care system and. Some microsponge related products are already approved;

\section{REFERENCES}

1. Mantry Shubhrajit, Bagchi Arnab, Das Sujit, Das Sudip, Microsponge as A Novel Stratergy of Drug Delivery System, Universal Journal of pharmaceutical science and research, 2015; 1(1):32-38.

2. Kumar Jaya raja, Muralidharan Selvadurai and Parasuraman Subramani, Evaluation of Antifungal Activity of Sustained Release Microsponge Enriched Fluconazole Gel for Penile Candidiasis in Male Rats, International Journal of PharmTech Research, 2014;6(6):1888-1897

3. Avhad Pawan S. and Patil Prashant B., A New Era In Topical Formulations - Microsponge Drug Delivery System International Journal of Pharmaceutical Science And Research, 2016; 7(7):2756-2761.

4. Muralidharan Selvadurai, Kumar Jaya raja, Ramasamy Sanggetha, Microsponges Enriched Gel (MEGs): A Novel Strategy for Opthalmic Drug Delivery System Containing Ketotifen, Journal of Pharmaceutical Science. \& Research 2013; 5(4):97-102.

5. Pathan Adil, Sanghshetti, Microsponge in Drug Delivery: A Review, International Journal of Parenteral and Dermatology, 2017; 1(1):32-35.

6. Deshwal Shikha and Saxena Ashwin Kumar, Micreosponge Delivery System: An Overview International Journal of Biopharmaceutics. 2014; 5(1):39-46.

7. Jadhav Namrata, Patel Vruti, Mungekar Siddesh, Bhamare Gaurav, Karpe Manisha, Kadams Vilasrao, Microsponge Delivery System: An updated review, current status and future prospects Journal of Scientific and Industrial Research, 2013; 2(6):1097-1110.

8. Gupta Akashdeep, Dhyani Archana and Juyal Divya , Microsponges laden gels for topical delivery: A novel approach The Pharma Innovation Journal 2016; 5(6): 39-43.

9. Kawashima Yoshiaki, Niwa Toshiyuki , Takeuchi Hirofumi , Hino Tomoaki , Ito Yoji, Control of Prolonged Drug Release and Compression Properties of Ibuprofen Microsponges with Acrylic Polymer, Eudragit RS by Changing their Intraparticle porosity, Chemical \& Pharmaceutical bulletin 1992;40(1):196-201.

10. Kaity Santanu, Maiti Sabyasachi, Ghosh Ashoke Kumar, Pal Dilipkumar, Ghosh Animesh , Banerjee Subham, Microsponge: A Novel Strategy For Drug Delivery System, Journal of Advanced Pharmaceutical Technology and Research, 2010; 1:283-290.

11. Nanda Shivani, Microsponge drug delivery syatem: an overview, World Journal of Pharmacy and Pharmaceutical sciences, 2013; 2(3):1032-1043. several products are currently under development and clinical assessment.

\section{CONCLUSION}

The microsponge delivery system is a novel technology for the controlled release of macroporous beads, loaded with an active agent, offering a potential reduction in side effects and maintaining their therapeutic efficacy. The microsponge drug delivery system is believed to reduce side effects, improved stability, increased elegance, enhanced formulation flexibility and also offers entrapment of its ingredients. Microsponge systems are non-irritating, non-mutagenic, nonallergenic, and nontoxic. This technology is being used currently in cosmetics, over-the-counter skin care, sunscreens, and prescription products. This kind of drug delivery technology may lead to a better understanding of the healing of several diseases.

12. Patil Shital S., Dandekar Vaishali, Kale Asawari And Barhate Dr. S. D., Microsponge Drug Delivery System: An Overview European Journal of pharmaceutical and Medical Research, 2016;3(8):212-221

13. Aritomi H, Yamasaki Y, Yamada K, Honda H, Koshi M. Development of sustained release formulation of chlorpheniramine maleate using powder coated microsponges prepared by dry impact blending method. Journal of Pharmceutical Science and Technology, 1996; 56(1):49-56.

14. Charde M. S. , Ghanawat P. B., Welankiwar A. S., Kumar J. And Chakole R. D. Microsponge A Novel New Drug Delivery System: A Review International Journal Of Advances in Pharmaceutics, 2013; 2(6).

15. Jagtap S.C, Karale A.A and Ambekar A.W Microsponge:A Novel Topical Drug Delivery System, Journal Of Drug Delivery Research, 2014; 3(4).

16. Vikrant K, Nikam, Dolas RT, Somwanshi SB, Gaware V.M., Kotade K.B., Dhamak K.B., Khadse A.N. and Kashid V.A., Microparticles: a novel approach to enhance the drug delivery - a review, IJPRD, 2011; 3(8):170-183.

17. Chainesh N. Shah And Dhiren P. Shah Microsponges: A Revolutionary Path Breaking Modified Drug Delivery of Topical Drugs International Journal of Pharmaceutical Research, April-June 2014; 6(2).

18. Jelvehgari M, Siahi-Shadbad MR, Azarmi S, Gary P, Martin, Nokhodchi A., The microsponge delivery system of benzoyl peroxide: Preparation, characterization and release studies, International Journal of Pharmaceutics, 2006; 308(1-2):124132.

19. Mandava Shyam Sunder And Thavva Vedavathi, Novel Approach: Microsponge Drug Delivery System International Journal Of Pharmaceutical Science And Research, 2012; 3(4).

20. Comoglu T, Gonul N, Baykara T, The effects of pressure and direct compression on tabletting of microsponges, International Journal of Pharmaceutics, 2002; 242(1-2):1915.

21. Patel Archana, Upadhyay Pratik, Trivedi Jatin, Shah Shreeraj And Patel Jaymin Microsponges as the versatile tool for Topical route: A Review, International Journal of Pharmaceutical Science And Research, 2012; 3(9):2926-2937.

22. Aloorkar N.H., Kulkarni A.S., Ingale D.J. and Patil R.A., Microsponges as Innovative Drug Delivery Systems, International Journal of Pharmaceutical Sciences and Nanotechnology, 2012; 5(1).

23. Mahajan AG, Jagtap LS and Chaudhary AL, Swami Sima P, Formulation \& evaluation of Microsponge drug delivery 
system using Indomethacin. International Research Journal of Pharmacy 2011; 2(10): 64-69

24. Kaur R., Kaur S. Role of polymers in drug delivery. Journal of Drug Delivery and Therapeutics, 2014; 4(3):32-36. https://doi.org/10.22270/jddt.v4i3.826

25. Joshi Garish, kaur Rajandeep and kaur Harpreet, International Research Journal of Pharmaceutical and Biosciences, 2016; 3(1):01- 11.

26. Saboji JK, Manoi FV, Gadad AP and Patel BD: Formulation \& evaluation of ketoconazole microsponge gel by Quasi emulsion solvent diffusion. Journal of Cell \& Tissue Research 2011; 11:2691-2696.

27. Kumari Pushpa, Mishra Shashi Kiran, A Comprehensive Review On Novel Microsponges Drug Delivery Approach, Asian Journal of Pharmaceutical and Clinical Research, 2016; 9(1):25-30.

28. Kavya Lalitha S, Shankar M, Likhitha D, Dastagiri J, Niranjan Babu M, A Current View on Microsponge Drug Delivery System European Journal of Molecular Biology And Biochemistry 2016; 3(1):33-38.

29. Nikam Vikrant K., RT Dolas, SB Somwanshi, VM Gaware, KB Kotade, KB Dhamak, AN Khadse and VA Kashid, Microparticles: a novel approach to enhance the drug delivery - a review, International Journal of Pharmaceutical Research and Development, 2011;3(8):170- 183.

30. Gandhi Sanket, Dol Hemalata, Ghorpade Sagar, Microsponge: A Prominent Strategy to Accelerate Performance of Topical Formulation, International Journal of Pharmacy and Pharmaceutical Research, 2016; 7(3).

31. Rajurkar VG, Tambe AB and Deshmukh VK, Topical AntiInflammatory Gels of Naproxen Entrapped in Eudragit Based Microsponge Delivery System, Journal of Advvanced Chemical Engineering, 2015, 5:2.

32. Nawal A. Rajab, Mohammad S. Jawad Formulation and In Vitro Evaluation of Piroxicam Microsponge as a Tablet, International Journal of Pharmacy And Pharmaceutical Sciences, 2016; 8(2).

33. Jain N, Sharma PK, Banik A, Recent advances on microsponge delivery, International journal of Pharmaceutical Sciences Review and Research, 2011:8(2).

34. Deore Mayuri B, Salunkhe K.S., Pawbake G., Chaudhari S.R. and Gaikwad P.R.Microsponges As A Modified Drug Delivery System World Journal of Pharmaceutical Research, 4(3):657-667.

35. Engla G., Soni L., Dixit V. Sustained release delivery of repaglinide by biodegradable microspheres. Journal of Drug Delivery and Therapeutics, 2017; 7(7):77-80. https://doi.org/10.22270/jddt.v7i7.1593

36. Upadhye Shashikant S., Kothali B.K., Apte A.K., Patil A.A., Danole A.B., A Review On Microsponge Drug Delivery System, International Journal of Pharmaceutical Research and Bio-science, 2016; 5(1):152-166.

37. Yerram Chandramouli, Shaik Firoz, B. Rubia Yasmeen, Amaravathi Vikram, B. Mahitha, U. Aruna Microsponges: A Novel Drug Delivery System For Controlled Delivery Of Topical Drugs International Journal Of Pharmaceutical Research \& Analysis, 2012; 2(2):79-86.

38. Jain Vikas and singh Ranjit, Dicyclomine-loaded eudragit based microsponge with potential for colonic delivery Preparation and characterization, Tropical Journal of Pharmaceutical Research, 2010; 9(1):67-72.

39. Orlu M, Cevher E, Araman A Design and evaluation of colon specific drug delivery system containing Flurbiprofen microsponges, International Journal of Pharmaceutics, 2006; 318(1-2):103-117.

40. Ade Pavan Kumar, Bhalerao Pravin, Khan Arshiya, Shahi S.R, Tadwee Imran Microsponge Drug Delivery System: A
Review, International Journal of Parenteral And Dermatology, 2017; 1(1):33-44

41. Singh S., Koland M. Formulation and evaluation of pulsatile drug delivery systems of glipizide for the management of type-II diabetes mellitus. Journal of Drug Delivery and Therapeutics, 2016; 6(1):11-18. https://doi.org/10.22270/jddt.v6i1.1192

42. Embil K. and Nacht, The Microsponge delivery system: a topical delivery system with reduced irritancy incorporating multiple triggering mechanisms for the release of actives, Journal of Microencapsulation 1996; 13(5):575-88.

43. Kapoor D, Vyas RB, Lad C, Patel M, Tyagi B, A Review On Microsponge Drug Delivery System Journal of Drug Delivery and Therapeutics, 2014; 4(5):29-35. https://doi.org/10.22270/jddt.v4i5.978

44. Kumar Saurabh, Tyagi L.K., and Singh Dashrath, Microsponge Delivery System (Mds): A Unique Technology For Delivery of Active Ingredients International Journal of Pharmaceutical Science and Research, 2011; 2(12):3069-3080.

45. Dasthagiri S, Jagadeesh P, Thirumallesh Naik SB, Nethravani G, Over Review of Microsponges - Advanced Novel Technology, World Journal of Pharmacy And Pharmaceutical Sciences, 5(2):414-426.

46. Kapoor D., Patel M., Vyas R., Lad C., Lal B. Site specific drug delivery through nasal route using bioadhesive polymers. Journal of Drug Delivery and Therapeutics, 2015; 5(1):1-9. https://doi.org/10.22270/jddt.v5i1.873

47. Shaheen S Z, Bolla K, Vasu K \& Singara C M A., Antimicrobial activity of the fruit extracts of Coccinia indica, African Journal of Biotechnology, 2009; 8(24):7073-707.

48. Tile Manisha K. And Pawar A.Y., Microsponges: A Novel Strategy For Drug Delivery, International Journal of Pure and Applied Bioscience, 2015; 3(1):224-235

49. Francesco Trotta, Marco Zanetti1 and Roberta Cavalli, Cyclodextrin-based nanosponges as Drug carrier. Beilstein Journal of Organic Chemistry, 2012; 8:2091-2099.

50. Jain V., Singh R. Development and characterization of eudragit RS 100 loaded microsponges and its colonic delivery using natural polysaccharides. Acta Poloniae Pharmaceutica Drug Research, 2010; 67:407-415.

51. Moin Afrasim , Deb Tamal K. , Osmani Riyaz Ali M., Bhosale Rohit R. , and Hani Umme, Fabrication, characterization, and evaluation of microsponge delivery system for facilitated fungal therapy, Journal of Basic and Clinical Pharmacy, 2016; 7(2):39-48.

52. Srivastava R, Pathak K, Micosponges: a futuristic approach for oral drug delivery, Expert Opinion on Drug Delivery, 2012; 9(7): 863-878.

53. Rastogi V., Shukla S., Singh R., Lal N., Yadav P. Microspheres: a promising drug carrier. Journal of Drug Delivery and Therapeutics, 2016; 6(3):18-26. https://doi.org/10.22270/jddt.v6i3.1196

54. Gandhi Arijit, Jana Sougata, Sen Kalyan Kumar Tailoring Effect of Microsponge For Targeted Drug Delivery Journal of Scientific and Innovative Research 2013; 2 (6):1073-1082

55. D'souza John I. and More Harinath N., Topical AntiInflammatory Gels of Fluocinolone Acetonide Entrapped in Eudragit Based Microsponge Delivery System, Research Journal of Pharmacy and Technology, 2008; 1(4):502-506.

56. http://www.wipo.int/patentscope/en

57. http://www.microsponge.com/images/microspongeparticle.jpg

58. Jain NK, Advances in controlled and novel drug delivery, New Delhi: CBS Publishers and Distributors, 2003: 89-91.

59. Martin A., Swarbrick J. \& Cammarrata A., In: Physical Pharmacy- Physical Chemical Principles in Pharmaceutical Sciences. 3rd Ed., 1991 pp. 527

60. Vyas SP and Khar RK: Targeted \& controlled drug delivery. 1st edition, CBS Publication, 2002. 